Soc. Sci. \& Med. 1973, Vol. 7, pp. 495-505. Pergamon Press. Printed in Great Britain.

\title{
THE PROMOTION OF INTEREST IN THE ROLE OF THE PHYSICIAN ASSOCIATE AS A POTENTIAL CAREER OPPORTUNITY FOR NURSES: AN ALTERNATIVE STRATEGY
}

\author{
RichaRd E. DARNELL \\ University of Michigan, Ann Arbor, Michigan, U.S.A.
}

\begin{abstract}
Several frameworks are presented for understanding the development of interest in the role of the Physician Associate as a potential career opportunity for nurses. The contribution of professional role identification with nursing, medicine, and amalgamation of the two professions are explored as a basis for career choice. The usefulness of the current mobility model in health careers emphasizing differential vertical and horizontal mobility is contrasted with a classical sociological mobility model. Deficiencies are noted in both professional role identification and mobility models employing horizontal and vertical mobility as a basis for the development of interest in the role of the Physician Associate as a potential career opportunity for nurses.

An examination of the factors implicit in the development of the Physician Associate in the emerging nations leads to significant understandings with regard to the development of interest in assuming some roles in those settings. Such cross cultural considerations make possible an integrated approach for understanding interest development of the Physician Associate. Attention is focused upon interest development as a function of:

1. Individual competencies.

2. Aspirational patterns.

3. The structure of opportunities which are made available, as well as upon specific career strategies.

Examination of these factors indicates that a major deterrent to career development by nurses in the role of Physician Associate is the pervasive psycho-sexual deference associated with current nursing practice. Attention to this factor in both training and practice settings is imperative in order to facilitate role alteration by nurses.
\end{abstract}

THE ROLE of the physician associate has received considerable worldwide attention in the past few years in response to the current crisis in health care delivery. There are several diverse frameworks for understanding the development of interest in this new role by members of the nursing profession. One major approach has been to view the development of interest in the role of the physician associate as a function of professional role identification. A second approach holds that this development is a function of career mobility patterns. The purpose of this paper is to attempt to analyze the relative merits of each of these approaches and offer some viable alternatives for the future selection of this career opportunity by nurses.

THE DEVELOPMENT OF INTEREST IN THE PHYSICIAN ASSOCIATE BY NURSES AS A FUNCTION OF PROFESSIONAL ROLE IDENTIFICATION

A review of the extensive literature related to the concept of the physician associate indicates that the evolution of interest in this role is often portrayed as a complex interaction of a large number of significant variables related to professional role identification. These can be subdivided into three major categories:

(1) Those factors which suggest the development of interest in the physician associate occur as a function of an expansion of the profession of nursing. 
(2) Those factors which suggest the development of interest in the physician associate occur as a function of an extension of the profession of medicine.

(3) Those factors which suggest the development of interest in the physician associate occur as a function of an amalgamation of the professions of nursing and medicine.

\section{INTEREST DEVELOPMENT IN THE ROLE OF THE PHYSICIAN ASSOCIATE AS A FUNCTION OF THE EXPANSION OF NURSING}

The evolution of the role of the nurse has been influenced by changes in the methods of health care and delivery. The evolution of home care programs and the expansion of health services to a broader segment of the population in the past few years have provided impetus and direction for an expanded role for nursing. Increased professional preparation in nursing has also contributed to the foundation for the further expansion of the nurse's role. This increased preparation has created a new type of nurse clinical specialist who has had advanced university training in subject matters directly related to particular diagnostic classification of patients [1]. More significantly, a large body of evidence based upon recent research and demonstration projects indicates the expansion of nurses' roles into areas which traditionally have been thought of as being the unique province of medicine. In the United States, the nurse has been utilized recently in: (1) determining the nature and urgency of the patient's problem; (2) deciding how soon the patient should be seen by a doctor; and (3) assigning him to the appropriate clinic. A study of the final disposition of patients, undertaken before and after introduction of the nurse's new role, showed no significant change in assignments to various clinics [2]. Nurses teach birth control, do multiphasic geriatric screening and have expanded their roles in child health supervision in the Oak-Chip Experiment undertaken by the Alameda County Health Department in California [3]. Their effectiveness in an expanded role has also been demonstrated in an experimental program for the orthopedically disabled in New York City [4]. The utilization of nurse clinics for chronically ill patients whose disease processes are stabilized, in conjunction with a medical clinic when necessary, has provided an efficient approach to patient management [5]. The widespread use of the school nurse is often viewed as an expansion of the nurse's traditional responsibilities. Industrial nursing has also relied heavily upon the professional judgement of the nurse. Recent reports have indicated expansion of the nurse's role in the treatment of adult diabetes [6], patients with rheumatic arthritis [7], and psychosomatic disorders [8].

A major focus of the expansion of the nurse's role in the United States has occurred in the field of pediatrics. For several years, a team consisting of physicians and public health nurses has made joint visits to patients' homes to provide home visitation in pediatric and obstetrical care. At the end of the first year of the program, the physicians requested a reduction in their visits and an increase in the nurses' visits [9, 10]. A nurse well-baby program has also been in effect at Massachusetts General Hospital since 1963 [11]. In a similar program, the University of California at Berkeley and the Berkeley Health Department have successfully redefined the role of the nurse in the child health conference and in the provision of regular care. The child is seen by the nurse and the physician at the first visit, and thercafter, in the absence of specific problems, by the nurse regularly and the physician at widely spaced intervals $[12,13]$. In Lansing, Michigan the Christo Rey Children's Clinic is also establishing vital new roles and responsibilities for the public health nurse personnel [14]. The "House Call for Physicians" project in Lansing, Michigan is another local example of the extension of the traditional role of the nurse. An important 
experimental study has recently demonstrated the effectiveness of using a nurse rather than a physician as a family health care management specialist [15].

A major training program has been developed to prepare pediatric nurse practitioners at the University of Colorado School of Medicine, resulting in a realignment of functions traditionally performed by physicians and nurses [16]. A descrpition of their training indicates the broad sweep of the responsibilities which may be successfully assumed by a competent nurse practitioner.

In Canada nurses have also demonstrated their usefulness in replacement employment physical examinations. In one study of 12,733 cases, available physicians were involved in only 696 cases [17].

Some European countries have advanced further with the innovative use of nurses as physician's associates. In Sweden, three highly-trained, experienced nurses are assigned to each doctor. The Swedish nurse has the authority to admit patients to hospitals in some districts and is viewed as a colleague practitioner with the right to diagnose and treat [18].

\section{INTEREST DEVELOPMENT IN THE PHYSICIAN ASSOCIATE AS A FUNCTION OF AN EXTENSION OF MEDICINE}

The evolution of the nurse's expanded role has often been seen as a process of delegation by medicine. In any new system, it is imperative as a first prerequisite to examine the whole process of delegation itself [19]. "Delegation by a physician is the key to all new concepts of physician assistants". [20, p. 28].

Delegation consists of two basic approaches: (1) "limited delegation in which the superior must retain the authority to modify or reject ideas or decisions which do not meet with his approval"; and (2) "full delegation in which the superior has the right to decide (for himself) the decisions he must make himself, and those to be delegated. However, once the responsibility for making a decision or developing a solution has been placed in one's subordinates, the assumption is that the superior will accept or support the action regardless of whether he personally agrees with it or not. This means that subordinates are held responsible for results, not for developing solutions designed to obtain the approval of the superior." [21, p. 36]. Full delegation has a crucial advantage in patient care in that "a superior who reserves himself the authority to make final decisions may not always expect as satisfactory results as when full responsibility for solving certain problems is delegated on one's subordinates... " and "an important contribution of the full delegation attitude of the superior is that it influences subordinates toward constructive solutions of a problem on its own merits. In doing so, it helps to avoid any tendencies toward merely giving lip service to a superior's solution, or arguing with him, or of doing as directed with reduced motivation". [21, pp. 38-39]. It would appear, however, that the type of delegation practiced by the physician is partial. Three general principles appear to control delegation to nurses by physicians. They are: (1) A physician can lawfully delegate to nurses only those functions, procedures or duties which do not require the exercise of his professional judgement; (2) The nurse must have training and experience in the function, procedure or duty to be delegated by the physician; (3) All such functions, procedures or duties must be performed under the direction or supervision or upon the prescription of a physician [22].

The "practice of medicine" has been described as the primary professional responsibility of the physician for the total care of his patient. Under Wisconsin law, a physician is granted unlimited license. This is legislative recognition of his comprehensive training and his corresponding professional responsibility. Nurses are not granted such a license nor are they 
trained for such an overall responsibility. It should not be necessary to reiterate that a nurse cannot "practice medicine" or that a physician cannot, except in a genuine emergency, lawfully delegate the power to practice medicine to her wittingly or unwittingly. This is true even though the nurse is willing to perform a function that requires the exercise of the professional judgement of a physician. (Physician's Guidelines for Delegation of Duties and Functions to Nurses, Wisconsin Medical Society, 1968.)

To the doctor, any transfer of his traditional functions may mean that responsibility is also surrendered. Unless medical responsibility is viewed as a shared one, full delegation becomes impossible [23].

As presently constituted, there appear to be two major areas of nursing practice: one dependent on the physician's orders and the other not requiring the specific orders of a physician [24]. Full delegation of responsibility which may be wise therapeutically appears impossible under most present practice laws. However, it is significant to note that there is nothing in the ethical codes of either the nursing or medical profession which prevents full delegation [19].

INTEREST DEVELOPMENT IN THE ROLE OF THE PHYSICIAN ASSOCIATE AS A FUNCTION OF THE AMALGAMATION OF BOTH NURSING AND MEDICINE

There are two interwoven elements of medical teamwork: human components and organization. Both of these elements relate to: (1) a division of labor in which complex professional role components are reduced into less demanding components; and (2) the synthesis of the resulting components into a functioning system [25]. Implicit in these professional role components of the physician is both the "knowing" or scholar function and the "doing" or technical function [26]. The physician is also a trustee "since a crucial ingredient of his role is lacking unless he uses both his own knowledge and skill and that of others in trust for the patient, in the legal sense of that phrase" [25, p. 825]. There are also various combinations of "knowing and doing" in nursing practice. However, in the education of the physician, the major emphasis is on "knowing", while in the education of nurses the major emphasis is on "doing" [27]. Professional status and role are indeed significant factors for individual health practitioners; however, the crucial question for society is what combination of "knowing" and "doing" performed by persons with what kind of training and experience will produce the best results for patients.

Nursing and medicine are experiencing a change in the nature and extent of their work in relation to their past, each other and the public. A growing array of new specialized diagnostic and therapeutic techniques has produced an increasing interdependence of the nurse and physician [28]. These techniques have resulted in procedures and problems of judgement and responsibility in medical care today which cannot be clearly designated as being solely the province of either medicine or nursing. "Although physician and nurse generally exercise different means to obtain the goals they share, their collaboration in the process of arriving at a therapeutic program and the activities in which they both engage serve to blur the distinctive features of each role." [27, p. 773].

A crucial issue at the present time is whether these professionals must vigorously define their claims on particular techniques and procedures, or whether they can work together as true professionals to determine who can best assume responsibility for a particular aspect of a patient's care at a given point in time [27]. This issue affects far more than the professions of nursing and medicine. "A fuller definition of new or potential roles for all other health professionals is dependent upon whatever realignment of function is made in the 
central triad created by the patient, the physician and the nurse." $[19$, p. 110]. It is certain that the trend toward nurses making more medical decisions in the absence of doctors will grow because the pressure originally responsible for this trend, that is, the rapidly increasing complexity of medical care and shortage of physicians, will undoubtedly continue [29]. This position implies that those activities which can be performed by nursing personnel without increasing the risk of harm to patients, even though they were formerly customarily or historically carried out by physicians, should be an acceptable part of nursing.

\section{THE UTILIZATION OF MOBILITY MODELS IN INTEREST DEVELOPMENT IN THE ROLE OF THE PHYSICIAN ASSOCIATE}

A more productive approach may be to address the interest development in the role of physician associate utilizing a mobility model. One such model represents career mobility occurring in two dimensions: (1) the "career ladder" or vertical dimension; and (2) the "career lattice" or horizontal dimension [30]. The concept of career ladder implies a career pattern which would make it possible for qualified individuals in health care delivery to move with relative ease from the level of aide, to the assistant, to the fully qualified professional practitioner, to more responsible professional roles in a given health profession. The theoretical implications of such movement between these levels in an upward direction have been dealt with extensively in the career development literature [31, 32].

The concept of the "career lattice" or horizontal dimension of career mobility implies a career pattern which would provide a possibility for the lateral transfer between health professions. With recognition of educational and clinical components common to several health fields, entry to a new health career would be readily achievable by such lateral movement.

Until recently, career development in nursing had traditionally followed the vertical mobility pattern of other professions. Those nurses who had made contributions to patient care, teaching, administration, research and professional organizational functions enjoyed the rewards associated with intraprofessional vertical mobility. Another form of vertical mobility had been demonstrated by those who had left nursing for other professional careers which they perceived as offering greater rewards, beginning their preparation for those careers without having benefited formally from their previous educational or clinical experience in nursing.

Utilizing the concepts of vertical and horizontal mobility outlined above, the development of the new professional role of physician associate must be viewed as a major horizontal extension of the profession of nursing. Through this new role, it is postulated that the nurse benefits directly from her formal educational preparation and experience in nursing as she assumes greater responsibility and authority in the management of acute and chronic health care problems. This model is deficient because increased responsibility and authority is often viewed as a movement toward professional identification with medicine.

It should be noted that current theoretical conceptualizations [31, 33, 34] do not adequately provide a framework for understanding the vocational dynamics involved in interest development in horizontal mobility by members of health care professions. In addition, the mobility model developed by Perry for health care professions differs markedly from the mobility model which has been developed by occupational sociologists. This latter model may offer greater promise for understanding the development of interest in the role of the physician associate.

The concepts of vertical and horizontal mobility first appeared in the occupational 
sociology literature less than 25 years ago [35]. Vertical mobility was used by Sorokin to indicate a change in rank, and horizontal mobility was defined as a change in function. Seven years later, a spatial model to describe the relationship between vertical and horizontal mobility was developed [36]. "The position of an individual in any social system may be described by his rank in a hierarchical scheme of relationships, his functions as a participant in group life and his location in time and space ... visualized as a three dimensional graph of which one horizontal axis represents function, the intersecting horizontal axis represents distance, and the vertical axis is a status scale." [36, p. 59]. In this model, horizontal mobility is defined as a change of function, including both the technical and social functions which arise from group membership.

Utilizing this model, it is thus possible to perceive a membership in a new professional role such as the physician associate as being any point in that three dimensional space.

If one can estimate the position of the professional nurse in the three dimensional space, it is then possible to draw a mobility vector between the two points which indicates both the direction and the magnitude of the mobility existing between the role of the nurse and the physician associate. It is evident from this model that rarely, if ever, can career mobility be considered exclusively vertical or exclusively horizontal in nature. The health care mobility model thus differs from the sociological mobility model in one significant way: while the health care model permits movement to be either horizontal or vertical, the sociological model permits any interactional combination of horizontal and vertical mobility as a function of the work setting. The sociological mobility model thus effectively diminishes the inordinate effect of professional role identification in the health care model by focusing upon settings as a significant variable, and can assist in the provision of an adequate conceptual basis for understanding the development of interest in the role of the physician associate. Its weakness lies in its emphasis on status considerations.

\section{CROSS-CULTURAL CONSIDERATIONS}

In the highly developed nations, the development of the "extended role" of the nurse as a physician associate has been seen as evolutionary, while the non-nurse physician associate is viewed as innovative [37]. It should be emphasized that the need for physician associates in developing countries has been stressed repeatedly and has been the subject of much professional attention [38-40]. General and specific guidelines for training this type of personnel have been formulated by the World Health Organization [41, 42].

In an extremely thorough and thoughtful review of the need for and the establishment of this category of worker in developing countries, Vaughan has emphasized that "there is no generally accepted definition of what the medical assistant should be. He is not an internationally recognized health worker in the same way that nurse and health inspector are. Each country has evolved its own definition of this worker, and so most training programmers are only recognized within their own national boundaries ... Comparisons ... can be confusing and misleading." [43, p. 265].

This situation closely parallels that existing in the more highly developed nations, and a closer examination of the factors implicit in the development of the physician associate in the emerging nations leads to several significant understandings with regard to the development of interest in assuming such roles in those settings.

(1) Emphasis in the emerging nations appears to focus on the capacity of individuals trained to perform certain diagnostic and treatment procedures rather than associa- 
tion with a particular professional role. Criteria for admission to training programs are often dependent upon both the availability of suitable applicants and the nature and extent of their anticipated duties.

(2) Although increasing recognition is given to the importance of the social and cultural proximity of the physician associate with the patients he serves, career mobility toward the fully qualified medical officer is neither encouraged nor anticipated. "Training programs producing a sub-professional doctor or an assistant medical officer have nearly always run into difficulties over professional status," [43. p. 269]. Nevertheless, good career structure, incentives and adequate salary scales are seen to be extremely important [43, p. 269].

(3) Territorial parameters, political systems, or the state of economic development do not appear to influence the type of tasks which have been assigned to physician associates. Thus, in Israel, a family doctor-nurse team operates in a specific locale within the context of carefully defined duties delegated by physician to nurse [44], while in the U.S.S.R., the utilization of the Feldsher takes on very different characteristics in urban and rural practice [45].

(4) Not all attempts to produce and sustain physician associates programs continued to be supported. Strong resistance has been reported in Nigeria and in Bhore, India [43, p. 265].

\section{AN INTEGRATED APPROACH}

Cross-cultural considerations make possible an integrated approach for understanding interest development in the role of the physician associate. Thompson, Avery and Carlson note that most careers are a gradual expansion of skills, training and experience. According to this formulation, careers have three bases: (1) the competence of the individual; (2) the aspirational patterns of the individual; and (3) the structure of the opportunities made available to the individual [46]. They define four basic career strategies which, with minor modifications, can serve to specifically address the role of the physician associate: (1) the heuristic strategy in which one is oriented toward advancement without regard to professional or organizational boundaries; (2) the professional strategy in which the person is sensitive to opportunities within his profession and does not consider organizational boundaries to be important; (3) the organizational strategy in which one is concerned with opportunities within the employing institution; and (4) the stability pattern where the advantages of the present position exclude the possibility of mobility [46]. Interacting with these basic career strategies are four basic career patterns:

(1) The enterprise defined-early ceiling career which involves minimal advance preparation and minimal skill and aptitude expectations.

(2) The enterprise defined-late ceiling career which is typified by the mature practitioner who has advanced formal education and who changes functions within a specific setting as she looks for the best opportunities for her skills to be utilized. She reaches her potential late in her career.

(3) The colleague defined--early ceiling career in which skills can be transferred from organization to organization, but which are rather standardized in terms of potential rewards. Ceiling is reached early in the career through a strategy of stability; further advancement is sought in the form of unions or professional associations. 
(4) The colleague defined--late ceiling career in which career growth in various settings occurs as a function increasing personal competencies.

Professional role identification and mobility models appear to be lacking in cross-cultural central organizing concepts which are adaptable to the development of interest in the role of the physician associate by potential practitioners. In addition, recent research has demonstrated non-support for viewing the role of the physician associate as a function of professional role identification or as a function of career mobility.

In a recent study [47], nursing students at Michigan State University, in the United States, were exposed to occupational information booklets constructed by nursing and medical educators which represented the role of the physician associate as (1) an expansion of nursing, (2) an extension of medicine, or (3) an amalgamation of medicine and nursing. Measures were obtained of the stated interest in that role as a potential career opportunity, the information-seeking behavior regarding that role (manifest interest), and the amount of information retained (tested interest). Results of the study revealed no differential development of interest in the role of physician associate as a result of exposure to different occupational information booklets. Furthermore, there was no meaningful difference in interest development as a function of student level of training. A post-experimental interview with a sample of participants in the study indicated that interest development in the role of the physician associate may arise from an association of that role with a distinct new professional identity.

When one examines both the aspirational patterns and the structure of opportunities made available to nurses who wish to adopt an expanded or alternative career strategy, one comes face to face with the phenomena of role ascription on the basis of sex. Socialization patterns in the male dominated profession of medicine ascribe to the physician a directive perspective; while in nursing, a predominantly female profession, an acquiescence to physician authority is predominant. Indeed, both nursing and medicine have been increasingly vocal in pointing out the consequences of such sex-stereotyped roles and their cost in creativity and personnel and professional growth.

We have socialized nursing students to the submissive role. We have helped students to be
tactful and diplomatic to the point of obscuring their collaborative role. We have so filled nurs-
ing students with the fear of making a mistake that they are low risk takers. Along with
fostering this fear of making mistakes, we socialize our students to depend on the physician
and to be reluctant to accept responsibility and accountability for their own actions.
When we talk about changing roles, helping nurses to learn new skills is relatively easy.
Changing attitudes is a different pattern entirely. I believe that this is one of the major chal-
lenges facing nursing education at the present time [37, p. 976].

Bergman, an eminent American pediatrician, points out that nursing must take on a major role in making any changes in the health care system. He states that the endless charting of trivia, the making out of reports, and the degrading supervisory system lead women with capacity and interest in personal and professional development to fossilization and bitterness [48].

If sex-linked stereotypic professional roles impede the development of interest in nurses for career enlargement, the characteristics of specific work settings in which such interest develops become of critical importance.

The work situation and the institution itself are not simply places where people of various occupations and professions come together and enact standard occupational roles, either complementary or conficting. These locales constitute the arenas wherein such roles are forged and developed [49]. 
There has been careful attention to the location or purpose of such work settings in determining role definition. The "ethical code of nursing and medicine impel both professions to explore improvement of services even if this means yielding professional prerogatives ... specific ethical questions related to delegation of functions will depend on the determinants in the actual situation", [19. p. 110]. "The setting in which a person is used determines his skill level. Whether this person works in a hospital or in the office of a private physicial will ultimately determine what can be delegated from one group which has a broad general responsibility to another group whose responsibility may be more clearly defined" [50].

However, the psychosexual characteristics which mediate the listening, the sharing of views, the analyzing, critiquing and the maintenance or revision of such codes have not received adequate attention. If professional socialization models and work settings can be altered, nurses will become extremely viable candidates for expanded or altered roles. It is no accident that the female liberation movement has developed in consonance with the professional growth of nursing and the establishment of the role of the physician associate. " . . . it seems not too far fetched to say that the present demands of the neofeminists concern a shifting of the place of what has traditionally been women's professions in the whole complex of professional services", [51, p. 66]. Such "shifting" will require not only increasing opportunities for the development of competencies, but also the careful nurturing of aspirational patterns to insure risk taking and the capacity to deal with threat. Clearly both will be necessary, for while "would be professions" provide the greatest opportunity for distinct upward mobility, they "appear to provide the greatest threat to existing status of all professional statuses", [52, p. 693].

\section{CONCLUSION}

Stereotypic role identification and traditional concepts of vertical and horizontal mobility presently in vogue in addressing mobility in health care professions are inadequate to describe the cross-cultural dynamics of interest development in the role of the physician associate as a viable career option for nurses. Interest development in the role of the physician associate will occur to the extent that the individual nurse perceives herself to be competent, is desirous of professional growth and the opportunities are made available to her within the context of her own idiosyncratic career strategies and patterns. A major deterrent to interest development by nurses in the role of physician associate as a viable career option is the pervasiveness of psychosexual deference associated with current nursing practice. Attention to this factor in training and practice settings is imperative if nurses are to productively pursue career opportunities as physician associates.

\section{REFERENCES}

1. Johnson, D. E., Wilcox, J. A. and Momel, H. C. The clinical specialist as a practitioner, Am. J. Nursing, November, 67, 2298, 1967.

2. LeY, A. B. A physician's point of view. Nursing Outlook, 14, 47, 1966.

3. JohNSON, W. Nursing in the Oak-Chip experiment. Am. J. Nursing, 65, 89, 1965.

4. VAYDA, C. O. Nurses can take on more work. Nursing Outlook, 13, 57, 1965.

5. LewIS, C. E. and ReSNICK, B. Nurse clinics and progressive ambulatory patient care. New Engl.J. Med., $277,1236,1967$.

6. Guthrie, N., Runyan, J. W., Clark, G. and Marvin, O. Clinical nursing conferences: preliminary report. New Engl. J. Med., 270, 1411, 1964. 
7. Gavrin, J. B., Trusky, E., Albam, B. and Feinstein, A. R. Rheumatic fever in children and adolescents: epidemiological study of subsequent prophylaxis in streptococcal infections and clinical sequellae 11, maintenance and preservation of population. Ann. int. Med., 60 (supplement 5), 18, 1964.

8. Lewis, C. E. and Thurstone, H. The Dynamics of Nursing in Ambulatory Patient Care Research in Nursing. Washington, D.C.: U.S. Government Printing Office, 19, 1965.

9. Ford, P., SEacat, M. S. and Silver, G. A. The relative roles of the public health nurse and the physician in prenatal and infant supervision. Am. J. publ. Hlth, 56, 1097, 1966.

10. SeACAT, M. and Schlacter, L. Expanded nursing role in prenatal and infant care. Am. J. Nursing, 68, 822, 1968.

11. ConNeliy, J. P. Use of ancillary personnel in childrens' outpatient departments: new trends in extending medical services. Clin. Pediat., 4, 233, 1965.

12. SIEGAL, E. and BRYSON, S. A redefinition of the role of the public health nurses in child health supervision. Am. J. pub. Hlth, 53, 1015, 1963.

13. Siegal, E., Dillihey, R. and Fitzgerald, C. J. Role changes within the child health conference: attitudes and professional preparedness of public health nurse and physicians. Am. J. publ. Hlth, $55,832,1965$.

14. Lindstrom, C. J. Coordinator of Nursing Services, Michigan State University. Person interview, February 25, 1970.

15. Fink, E. et al. The management specialist in effective ambulatory care. Am. J. publ. Hlth, 56, 527, 1969.

16. Silver, H. and Ford, L. The pediatric nurse practitioner at Colorado. Am. J. Nursing, 67, 1443, 1967.

17. Bews, D. C. and BaILLIE, J. H. Preplacement health screening by nurses. Am. J. publ. Hlth, 59, 2178, 1969.

18. RICHARDS, D. H. Dilution in general practice. Lancet, 1, 9, 1966.

19. Pellegrino, E. D. Nursing and medicine-ethical implications in changing practice. Am. J. Nursing, 64, 107, 1964.

20. Medical World News, January 23, 1970, p. 28.

21. Solem, A. R. An evaluation of two attitudinal approaches to delegation. J. appl. Psychol., 42, 36, 1958.

22. Physicians guidelines for delegation of duties and functions to nurses. Wis. med. J., 67, 54, 1968.

23. LEVY, L. Factors which facilitate or impede transfer of medical functions from physicians to paramedical personnel. J. Hith Hum. Behav. 7, 50, 1966.

24. Anderson, B. and Lesnix, M. J. Nursing Practice and The Law, 2nd edn, pp. 259-260, Lippinott, New York, 1962.

25. MAGRAW, R. M. Interdisciplinary teamwork for medical care and health services. Ann. intern. Med. 69, 821, 1968.

26. Milus, J. S. A reexamination of assumptions in medical education. Lond. Gen. Pract. (Suppl.) 44, 1967.

27. SCHLOtFeldt, R: M. A mandate for nurses and physicians. Am. J. Nursing, 65, 102, 1965.

28. SHEP, C. G. and BACIIOR, M. E. Nursing and medicine-emerging patterns of practice. Am. J. Nursing, 64, $107,1964$.

29. PratT, H. The doctors' view of the changing nurse-physician relationship. J. med. Educ., 40, 767, 1965.

30. Perry, W. J. Career mobility in allied health education. J. Am. med. Ass. October 6, 1969, 210, (1), $107-110$.

31. Holland, J. L. Explorations of a theory of vocational choice: I. One and two year longitudinal studies. Psychol. Monogr., 76, 545, 1962.

32. RoE, A. Early determinants of vocational choice. J. Counseling Psychol, 4, 212, 1957.

33. Holland, J. L. Exploration of a theory of vocational choice and achievement: II. A four-year prediction study. Psychol. Reprints, 12, 547, 1963.

34. Super, D. E., Starishevsky, R., Matlin, N. and Jordan, E. Career Development: Self Concept Theory. College Entrance Examination Board, New York, 1963.

35. SOROKin, P. Society, Culture and Personality: Their Structure and Dynamics. Harper and Brothers, New York, 1947.

36. CaPlow, T. The Sociology of Work. NcGraw-Hill, New York, 1954.

37. DE TORNYAY, R. Two views on the latest health manpower issue: expanding the nurse's role does not make her a physician's assistant. $A m$. J. Nursing, 71, 974, 1971.

38. Chesterman, C. C. Auxiliary medical personnel in Africa. J. trop. Med. Hyg., 56, 123, 1953.

39. KING, M. Medical Care in Developing Countries. Oxford University Press, Nairobi, Kenya, 1966.

40. Rosinski, E. F. and Spencer, F. J. The Assistant Medical Officer. University of North Carolina Press, Chapel Hill, North Carolina, 1965.

41. The use and training of auxiliary personnel in medicine, nursing, midwifery and sanitation. Tech. Rep. Ser., Wld Hlth Ord., 212, 1961.

42. Training of medical assistants and similar personnel. Tech. Rep. Ser. Wld Hlth Org., 385, 1968.

43. Vaughan, J. P. Are doctors always necessary? A review of the need for the medical assistant in developing countries. J. trop. Med., 74, 265, 1971. 
44. Yodfat, Y. A new method of teamwork in family medicine in Israel with the participation of nurses as physician's assistants. Am. J. publ. Hlth, 62, 953, 1972.

45. The feldsher in the USSR. N. Z. med.J., 74, 261, 1971.

46. Thompson, J. D., Avery, R. W. and Carlson, R. Occupations, Personnel and Careers, pp. 5-6, 1962. Pittsburgh: Administrative Science Center, University of Pittsburgh, 1962.

47. Darnell, R. E. The influence of professional role identification upon the development of interest in horizontal career mobility by nursing students. Paper presented at American Educational Research Association, New York City, February 4, 1971.

48. Bergman, A. B. Two views on the latest health manpower issue: physician's assistants belong in the nursing profession. Am. J. Nursing, 71, 975, 1971.

49. Bucher, R. and Strauss, A. Professions in progress. Am. J. Sociol., 66, 325, 1961.

50. Fenninger, L. As quoted in the Am. med. News, 9, December 1, 1969.

51. Hughes, E. C. The professions in society. Can.J. Econ. polit. Sci. 26, 54, 1960; as found in Vollmer, H. M., and Mills, D. L. Professionalization, p. 6, Prentice Hall, Englewood Cliffs, 1966.

52. Reiss, A. J. Occupational mobility of professional workers. Am. sociol. Rev. 20, 693, 1955. 